\title{
A Study of the Performance Management Systems in the Indian Service and Industry Sectors
}

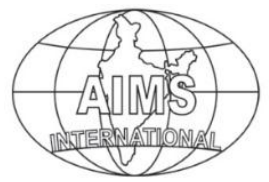

DOI: $10.26573 / 2017.11 .3 .2$

Volume 11, Number 3

September 2017, pp. 179-190

\author{
Merlyn Michael D'souza \\ Indian Education Society's Management \\ College \& Research Centre, India \\ (merl.dsouza7980@gmail.com) \\ Michael D'souza \\ HR Intelligence and Analytics, Bank of \\ America, India \\ (mikedsouza1979@yahoo.co.in)
}

\begin{abstract}
Specialists at firms like a human resource consulting and training firm and a consulting and training company as well as increasing numbers of $H R$ and operating executives, refer to the performance appraisal and its one-way feedback with its effectiveness outmoded by new competitive imperatives and changing employee expectations. The good term from the experts is that by managing performance instead of just performing appraisals, companies can improve employee and hence corporate performances along with saving managers considerable time and trouble. The paper attempts to study the performance management systems in the Indian service and industry sectors. There are three objectives of this research. They are as follows: (1) To list the description in details of the performance management systems used, (2) To compare the performance management systems across sectors, (3) To compare the performance management systems across different organization sizes. The description in details of the performance management systems is: Respondents agree that Individual and organization goals must be integrated and performance management systems should focus on developmental areas. Across sectors, there is a common agreement to defining performance management systems. Across different sizes of organizations differ in their perceptions on defining performance management systems based on whether Performance management systems should not be linked to pay and Performance measures must be quantifiable.
\end{abstract}

Keywords: Performance Management System, Performance Appraisal, Evaluation

\section{Introduction}

The services sector is a vital component of the Indian economy. The sector, which accounts for around 60 per cent of the country's gross domestic product (GDP), has emerged as one of the largest and fastest-growing sectors not just in the country but in the global landscape; subsequently, its contribution towards global output and employment has been substantial.

The share of services in India's GDP at factor cost (at current prices) rose from 33.3 per cent (1950-1951) to 56.5 per cent in 2012-13, as per advance estimates. During FY 2014-15, the sector is projected to grow at a healthy 5.6 per cent, according to National Council of Applied Economic Research (NCAER). This shows 
that the services sector is simply increasing though not through sharp surges, and is a future area to reckon with due to its steady growth. This sector in India comprises a wide range of activities, including trading, transportation, communication, financial, real estate and business services, and community, social and personal services (Govt. of India, ITP Division, Services Sector: Advantage India, India in Business, 2014).

According to a study by global management consulting firm McKinsey and Company, the manufacturing sector in India could grow six-fold to US\$ 1 trillion, by 2025. The rising demand in the country and the aspirations of multinational companies (MNCs) to establish low-cost plants in India, are seen as reasons for this possible growth. Up to 90 million domestic jobs could be created by that time, with the sector generating about 25-30 per cent of the country's gross domestic product (GDP). India's rapidly expanding economy gives domestic entrepreneurs and international players vast opportunities to invest and grow. India's manufacturing sector is vital for its economic progress. Its contribution to the GDP is 16 per cent, with the potential to grow more. The government has realized the importance of this sector to the country's industrial development, and has taken a number of proactive steps to further enhance the industry. Today, India's attractiveness as a manufacturing center for foreign companies is all too apparent. Overseas mobile phone and automobile companies already have manufacturing plants in India. Luxury brands such as Frette and Louis Vuitton are looking to do the same, as is major aircraft maker Airbus (Govt. of India, 2015).

The paper attempts to study the performance management systems in the Indian service and industry sectors combined. The disadvantages and advantageousness of the performance management systems used will be emphasized. This will decide which particular performance management system is best suited for a single firm in the industry and service sector each. There are three objectives of this research. They are as follows: (1) To list the description in details of the performance management systems used, (2) To compare the performance management systems across sectors, (3) To compare the performance management systems across different organization sizes.

\section{Literature Review}

Many people express simplified assumptions about the role of measurement in organizations. The Gartner Group, the US-based research consultancy, predicted that $60 \%$ of large U.S. firms had adopted the balanced scorecard by the end of 2001 . Major ERP vendors, such as Oracle and SAP, launched balanced scorecard reporting modules for their software in 2000. Survey data suggest that in the five years prior to 2000, around 50\% of companies attempted to transform their organizational performance measurement systems, while more recent data indicate that $85 \%$ of organizations will have performance measurement initiatives underway by the end of 2004 ( (Frigo, 105 (2000)); (Rigby, 43/2 (Winter 2001)); (Speckbacher, Bischof, \& Pfeiffer, 14/4 (December 2003)) (Marr, et al., 2004). Similar data can be found in Europe.

So what is new about these recent developments? One of the themes that emerge in the current literature is that performance measures have hidden value. They can support managers [and other organizational members] as they seek to clarify strategy, communicate strategy, and challenge assumptions (Neely \& Najjar, 2006). Putting a team of individual star performers together does not automatically lead to 
optimal organizational performance (O'Boyle, 2012). Companies can start leveling the playing field by redesigning their performance appraisal system with a few simple steps by crowd sourcing performance data throughout the year, train appraisers to give feedback about specific criteria, develop an appropriate appraisal scale and transform what feedback is meant to achieve (Cecchi-Dimeglio, April 12, 2017). Thus the need for listing the different descriptions of performance appraisals is determined. The differences in appraisal systems across different sizes of organizations and the sectors they belong to have thus been studied to get a clearer picture of the appropriate appraisal techniques.

\section{Research Design}

The research design is quantitative and descriptive in nature. The data is collected on the basis of structured questionnaire by interviewing the respondents in person. Here, the application of structured questionnaire method to the business context involves looking at how effective or ineffective is a performance management system used in the organization. There are 111 companies studied, in general. The data from these 111 companies is collected during the period, from 2014 to 2015. The respondents were HR managers and performance appraisal managers.

\section{Research Methodology}

The research design is quantitative in nature and also descriptive in nature. The data was collected on the basis of structured questionnaire. Respondents (HR Managers/ Performance Appraisal Managers) were interviewed in person. 'Simple random' sampling method is used here. A simple random sample is a subset of a statistical population in which each member of the subset has an equal probability of being chosen. An example of a simple random sample would be the names of 50 employees being chosen out of a draw from a company of 500 employees. HR employees of 111 randomly selected business organizations across varied sectors and different sizes were interviewed in the region of Greater Mumbai. 111 company's data is studied, and collected during the period, from 2014 to 2015.

\subsection{Value Analysis}

The following 5 factors are analyzed across the 111 organizations

1. What is Performance Management to the respondent?

2. Organizational Background

3. Nature of performance arrangements

4. Process of performance management followed

5. Performance management outcomes

\subsection{Hypotheses Formulation}

1. H10: There is no significant difference in average ratings of 'What is Performance Management to the respondent?' across public sector, private sector- service/ voluntary, private sector- manufacturing, other type of organizations.

2. H20: There is no significant difference in average ratings of 'What is Performance Management to the respondent?' across different sizes of organizations. 
3. H30: There is no specific preference indicated by respondents across public sector, private sector- service/ voluntary, private sector- manufacturing, other type and sizes of organizations for the major elements of the business strategy at present.

4. H40: There is no significant difference in average ratings of effectiveness of 'The different performance arrangements of annual appraisal, bi-annual appraisal, rolling appraisal, 360 degree appraisal, peer appraisal, self-appraisal, subordinate feedback, continuance/ competence assessments, objective-setting and review, performance-related pay, coaching and/ or mentoring, career management and/ or succession planning, personal development plans and any other' across public sector, private sector- service/ voluntary, private sectormanufacturing and other type of organizations.

5. H50: There is no significant difference in average ratings of effectiveness of 'The different performance arrangements of annual appraisal, bi-annual appraisal, rolling appraisal, 360 degree appraisal, peer appraisal, self-appraisal, subordinate feedback, continuance/ competence assessments, objective-setting and review, performance-related pay, coaching and/ or mentoring, career management and/ or succession planning, personal development plans and any other' across different sizes of organizations.

6. H60: There is no significant difference in average ratings of 'What is Performance Management in the respondent's organization?' across public sector, private sector- service/ voluntary, private sector- manufacturing and other type of organizations.

7. H70: There is no significant difference in average ratings of 'What is Performance Management in the respondent's organization?' across different sizes of organizations.

8. H80: There is no specific preference indicated by respondents across public sector, private sector- service/ voluntary, private sector- manufacturing, other type and sizes of organizations for the key factors which is used to determine whether performance management is effective.

\subsection{Data Collection}

The 5 factors were analyzed, by questionnaires, based on Sections A to E, and administered through seeking feedback by close and open-ended questions related to the 5 Factors. 111 company's trainee-level to mid-level HR/ Performance managers were interviewed. Prior appointments/ email communication were taken. They include industry and service sector companies in multiple domain areas.

\section{Data Processing Analyses and Interpretation}

By the Survey feedback method, the 5 factors were collectively analyzed. 111 companies with the corresponding sector they represented have been analyzed as per the following discussion.

Chronbach's alpha value is 0.779 , which is greater than 0.7 , for performance defining parameters, which determines that the data analysis is reliable. The survey has been conducted separately for 10-15 respondents as a pilot study and the questionnaire has been validated for content by 5 experts in this domain and for criterion based on consistent results in the pilot study. The standardized questionnaire instrument has been sourced from a book by a renowned expert in 
'Performance management Systems' authored by Michael Armstrong and Angela Baron (2006), Jaico publishing house. By the one-way Anova analyses, using the SPSS 16.0 tool, the following observations may be made with reference to Performance Management (PM) Systems. The following analyses may be compiled as below.

This may be started by the first factor.

Section A. What is Performance Management to the respondent? Across public sector, private sector- service/ voluntary, private sector- manufacturing and other section.

H10: There is no significant difference in average ratings of 'What is Performance Management to the respondent?' across public sector, private sector- service/ voluntary, private sector- manufacturing, other type of organizations.

H11: There is significant difference in average ratings of 'What is Performance Management to the respondent?' across public sector, private sector- service/ voluntary, private sector- manufacturing and other type of organizations.

As all values in the 'Sig.' column header are greater than the value of ' 0.05 '. Hence by applying ANOVA test to alternate hypothesis H11: As per ANOVA test, all values in 'Sig.' column header are greater than 0.05 , hence accept null hypothesis. Hence Bonferroni test is not used. Hence we conclude that 'There is no significant difference in ratings for 'what is Performance Management to the respondent?' across sectors.' The following points are important: H20: There is no significant difference in average ratings of 'What is Performance Management to the respondent?' across different sizes of organizations.

H21: There is significant difference in average ratings of 'What is Performance Management to the respondent?' across different sizes of organizations. As per the 'test of homogeneity of Variances', all values, except the one of 'Performance Management (PM) requires extensive communication' in the 'Sig.' column header are greater than the value of ' 0.05 ', hence on applying of ANOVA test to alternate hypothesis $\mathrm{H} 21$ in all other parameters. As per ANOVA test, all values, except 3 values, in 'Sig.' column header are greater than 0.05 . Also, one value does not have homogeneity of variance. Hence Bonferroni test is used in the remaining 2 values of 'PM should be distanced from pay' and 'PM measures should be quantifiable'. As per 'Bonferroni' test used, the remaining 2 values of 'PM should be distanced from pay' and 'PM measures should be quantifiable' is discussed. As per parameter, 'PM should be distanced from pay' organization sizes of 50-99 members and 500-999 members differ on their views that 'PM should be distanced from pay'. Similarly, for the parameter 'PM measures should be quantifiable' organization sizes of 1000 plus members and 100-499 members differ on their views that 'PM measures should be quantifiable'.

Hence we conclude that 'There is no significant difference in ratings for 'what is Performance Management to the respondent?' across sizes of organization except for the parameters of 'PM should be distanced from pay' and 'PM measures should be quantifiable'. As per the average ratings all respondents are depicted. The ratings are measured on a scale of ' 1 ' to ' 4 ', where ' 1 ' is 'strongly disagree' and ' 4 ' is 'strongly agree'. The lowest ratings, which respondents 'slightly disagree' with are, 'Performance Management distracts people from more important core activities' and 'Performance Management should be distanced as far as possible from payment 
systems'. The highest ratings, in which respondents 'slightly agree' with are 'Performance Management will only succeed if it integrates the goals of individuals with those of the organization' and 'the focus of performance management system should be developmental'.

This is continued by the second factor.

\section{Section B. Organizational Background}

2 tabulated SPSS output results are described in the following sections. H30: There is no specific preference indicated by respondents across public sector, private sector- service/ voluntary, private sector- manufacturing, other type and sizes of organizations for the major elements of the business strategy at present.

H31: There is a specific preference indicated by respondents across public sector, private sector- service/ voluntary, private sector- manufacturing, other type and sizes of organizations for the major elements of the business strategy at present. 'Friedman test' is conducted at $95 \%$ confidence level, or the 0.05 level of significance. Since 'Asymptotic Sig.' value of 0.000 is less than 0.05 , as per SPSS Output, we reject null hypothesis $\mathrm{H} 30$

Hence, as per SPSS Output, 'Increase productivity' followed by 'Improve quality' is the highest ranked elements for the major elements of the business strategy at present. Also, 'Other' followed by 'Reduce headcount' is the lowest ranked elements for the major elements of the business strategy at present.

This is continued by the third factor.

Section C. Nature of current performance arrangements across public sector, private sector- service/ voluntary, private sector- manufacturing, other type and sizes of organizations. 5 tabulated SPSS output results are described in the following sections. H40: There is no significant difference in average ratings of effectiveness of 'The different performance arrangements of annual appraisal, bi-annual appraisal, rolling appraisal, 360 degree appraisal, peer appraisal, self-appraisal, subordinate feedback, continuance/ competence assessments, objective-setting and review, performance-related pay, coaching and/ or mentoring, career management and/ or succession planning, personal development plans and any other' across public sector, private sector- service/ voluntary, private sector- manufacturing and other type of organizations.

H41: There is significant difference in average ratings of effectiveness of 'The different performance arrangements of annual appraisal, bi-annual appraisal, rolling appraisal, 360 degree appraisal, peer appraisal, self-appraisal, subordinate feedback, continuance/ competence assessments, objective-setting and review, performancerelated pay, coaching and/ or mentoring, career management and/ or succession planning, personal development plans and any other' across public sector, private sector- service/ voluntary, private sector- manufacturing and other type of organizations.

As per SPSS Output, in the 'test of homogeneity of Variances', all values, except the ones of 'rolling appraisal', 'self-appraisal', 'continuance assessments', 'competence assessments', and 'objective-setting and review' in the 'Sig.' column header are greater than the value of ' 0.05 ', hence by ANOVA test to alternate hypothesis $\mathrm{H} 41$ in all other parameters.

As per SPSS Output, and as per ANOVA test, all values, in 'Sig.' column header are greater than 0.05 . Also, earlier 5 values do not have homogeneity of variance. 
Hence Bonferroni test is not used. Hence we accept null hypothesis here and conclude that 'There is no significant difference in average ratings of effectiveness of 'The different performance arrangements of annual appraisal, bi-annual appraisal, rolling appraisal, 360 degree appraisal, peer appraisal, self-appraisal, subordinate feedback, continuance/ competence assessments, objective-setting and review, performance-related pay, coaching and/ or mentoring, career management and/ or succession planning, personal development plans and any other' across public sector, private sector- service/ voluntary, private sector- manufacturing and other type of organizations.'

The following is to be noted

H50: There is no significant difference in average ratings of effectiveness of 'The different performance arrangements of annual appraisal, bi-annual appraisal, rolling appraisal, 360 degree appraisal, peer appraisal, self-appraisal, subordinate feedback, continuance/ competence assessments, objective-setting and review, performancerelated pay, coaching and/ or mentoring, career management and/ or succession planning, personal development plans and any other' across different sizes of organizations.

H51: There is significant difference in average ratings of effectiveness of 'The different performance arrangements of annual appraisal, bi-annual appraisal, rolling appraisal, 360 degree appraisal, peer appraisal, self-appraisal, subordinate feedback, continuance/ competence assessments, objective-setting and review, performancerelated pay, coaching and/ or mentoring, career management and/ or succession planning, personal development plans and any other' across different sizes of organizations.

As per SPSS Output, in the 'test of homogeneity of Variances', all values, except the 5 ones of 'rolling appraisal', 'continuance assessments', 'objective-setting and review', 'Performance-related pay', and 'Coaching and/ or mentoring' in the 'Sig.' column header are greater than the value of ' 0.05 ', hence by using ANOVA test to alternate hypothesis $\mathrm{H} 51$ in all other parameters.

As per SPSS Output, and as per ANOVA test, all values, in 'Sig.' column header are greater than 0.05 . Also, earlier 5 values do not have homogeneity of variance. Hence Bonferroni test is not used. Hence we accept null hypothesis here and conclude that 'There is no significant difference in average ratings of effectiveness of 'The different performance arrangements of annual appraisal, bi-annual appraisal, rolling appraisal, 360 degree appraisal, peer appraisal, self-appraisal, subordinate feedback, continuance/ competence assessments, objective-setting and review, performance-related pay, coaching and/ or mentoring, career management and/ or succession planning, personal development plans and any other' across different sizes of organizations.'

As per SPSS Output, the average ratings of all respondents are depicted. The ratings are measured on a scale of ' 1 ' to ' 6 ', where ' 1 ' is 'not a feature', ' 2 ' is 'very effective feature', ' 3 ' is 'mostly effective', ' 4 ' is 'partly effective', ' 5 ' is 'not effective' and ' 6 ' is 'is a feature'. The ratings, which respondents are found tending towards with 'partly effective feature' are 'self-appraisal' and 'other' types. The ratings, in which respondents are found tending towards with, 'very effective feature' are 'competence assessments', and 'objective-setting and review'.

This is continued by the fourth factor. 
Section D. Process of performance management in the organization of respondent, across public sector, private sector- service/ voluntary, private sector- manufacturing, other type and sizes of organizations. 5 tabulated SPSS output results are described in the following sections.

H60: There is no significant difference in average ratings of 'What is Performance Management in the respondent's organization?' across public sector, private sectorservice/ voluntary, private sector- manufacturing and other type of organizations.

H61: There is a significant difference in average ratings of 'What is Performance Management in the respondent's organization?' across public sector, private sectorservice/ voluntary, private sector- manufacturing and other type of organizations. As per SPSS Output, in the 'test of homogeneity of Variances', all values, except the highlighted ones of 'Performance-related pay is an essential part of performance management', and 'Performance Management sets stretching \& challenging goals', in the 'Sig.' column header are greater than the value of ' 0.05 ', hence ANOVA test is applied to alternate hypothesis H61 in all other non-highlighted parameters.

As per SPSS Output, and as per ANOVA test, all values in 'Sig.' column header are greater than 0.05 , hence, we accept null hypothesis. Hence Bonferroni test is not used. Hence we conclude that 'There is no significant difference in average ratings of 'What is Performance Management in the respondent's organization?' across public sector, private sector- service/ voluntary, private sector- manufacturing and other type of organizations'.'

H70: There is no significant difference in average ratings of 'What is Performance Management in the respondent's organization?' across different sizes of organizations.

H71: There is a significant difference in average ratings of 'What is Performance Management in the respondent's organization?' across different sizes of organizations. As per SPSS Output, in the 'test of homogeneity of Variances', all values, in the 'Sig.' column header are greater than the value of ' 0.05 ', hence by using ANOVA test to alternate hypothesis $\mathrm{H} 71$ in all parameters. As per SPSS Output and as per ANOVA test, all values in 'Sig.' column header are greater than 0.05 , hence, we accept null hypothesis. Hence Bonferroni test is not used. Hence we conclude that 'There is no significant difference in average ratings of 'What is Performance Management in the respondent's organization?' across different sizes of organizations'.

As per SPSS Output, the average ratings of all respondents are depicted. The ratings are measured on a scale of ' 1 ' to ' 4 ', where ' 1 ' is 'strongly disagree' and ' 4 ' is 'strongly agree'. The lowest ratings, which respondents 'slightly disagree' with are, 'Performance management is bureaucratic and time-consuming'. The highest ratings, in which respondents 'slightly agree' with are 'Performance-related pay is an essential part of performance management'.

This may be continued by the final fifth factor.

Section E. Performance management outcomes. 2 tabulated SPSS output results are described in the following sections. H80: There is no specific preference indicated by respondents across public sector, private sector- service/ voluntary, private sectormanufacturing, other type and sizes of organizations for the key factors which is used to determine whether performance management is effective. 
H81: There is a specific preference indicated by respondents across public sector, private sector- service/ voluntary, private sector- manufacturing, other type and sizes of organizations for the key factors which is used to determine whether performance management is effective. Let us conduct 'Friedman test' at 95\% confidence level, or at the 0.05 level of significance. Since 'Asymptotic Sig.' value of 0.000 is less than 0.05, as per SPSS Output, we reject null hypothesis H81

Hence, as per SPSS Output, 'Achievement of financial targets' followed by 'Improved customer care' is the highest ranked elements as the key factors which is used to determine whether outcomes of performance management is effective. Also, 'Other' followed by 'Motivation' is the lowest ranked elements as the key factors which is used to determine whether outcomes of performance management is effective.

\section{Findings and Conclusions}

The research analyzed performance management systems of 111 firms gave the following summary of findings and conclusions

1. There is no significant difference in ratings for 'what is Performance Management to the respondent?' across sectors. Across sectors there is a common agreement to defining performance management systems.

2. There is no significant difference in ratings for 'what is Performance Management to the respondent?' across sizes of organization except for the parameters of 'PM should be distanced from pay' and 'PM measures should be quantifiable'. Different sizes of organizations differ in their perceptions on defining performance management systems based on whether Performance management systems should not be linked to pay and Performance measures must be quantifiable.

3. The lowest ratings, which respondents 'slightly disagree' with are, 'Performance Management distracts people from more important core activities' and 'Performance Management should be distanced as far as possible from payment systems'. The highest ratings, in which respondents 'slightly agree' with are 'Performance Management will only succeed if it integrates the goals of individuals with those of the organization' and 'the focus of performance management system should be developmental' The respondents disagree that performance management systems distract people from core activities and should be distanced from payment systems. Respondents agree that Individual and organization goals must be integrated and performance management systems should focus on developmental areas.

4. 'Increase productivity' followed by 'Improve quality' is the highest ranked elements for the major elements of the business strategy at present. Also, 'other' followed by 'Reduce headcount' is the lowest ranked elements for the major elements of the business strategy at present.' Most organizations that participated as respondents had their main business strategy as 'Increase productivity' and 'Improve quality' and definitely very few were focusing on 'reduce headcount' as their business strategy.

5. There is no significant difference in average ratings of effectiveness of 'The different performance arrangements of annual appraisal, bi-annual appraisal, rolling appraisal, 360 degree appraisal, peer appraisal, self-appraisal, subordinate feedback, continuance/competence assessments, objective-setting 
and review, performance-related pay, coaching and/ or mentoring, career management and/ or succession planning, personal development plans and any other' across public sector, private sector- service/ voluntary, private sectormanufacturing and other type of organizations. All respondents across sectors did not differ much in their opinions on effectiveness of a particular method of performance appraisal.

6. There is no significant difference in average ratings of effectiveness of 'The different performance arrangements of annual appraisal, bi-annual appraisal, rolling appraisal, 360 degree appraisal, peer appraisal, self-appraisal, subordinate feedback, continuance/ competence assessments, objective-setting and review, performance-related pay, coaching and/ or mentoring, career management and/ or succession planning, personal development plans and any other' across different sizes of organizations. All respondents across different sizes of organizations did not differ much in their opinions on effectiveness of a particular method of performance appraisal.

7. The ratings, which respondents are found tending towards with "partly effective feature' are 'self-appraisal' and 'other' types. The ratings, in which respondents are found tending towards with, 'very effective feature' are 'competence assessments', and 'objective-setting and review' Competence assessments and Objective-setting review were considered as very effective methods of appraisal.

8. There is no significant difference in average ratings of 'What is Performance Management in the respondent's organization?' across public sector, private sector- service/ voluntary, private sector- manufacturing and other type of organizations' All respondents' views on defining their performance management systems across sectors were similar.

9. There is no significant difference in average ratings of 'What is Performance Management in the respondent's organization?' across different sizes of organizations' All respondents' views on defining their performance management systems across different sizes of organizations were similar.

10. The lowest ratings, which respondents 'slightly disagree' with are, 'Performance management is bureaucratic and time-consuming'. The highest ratings, in which respondents 'slightly agree' with are 'Performance-related pay is an essential part of performance management' Most respondents disagree that Performance management systems are bureaucratic. Also, most respondents tend to agree that performance-related pay is an essential part of performance management systems.

11. 'Improved customer care' is the highest ranked elements as the key factors which is used to determine whether outcomes of performance management is effective. Also, 'Other' followed by 'Motivation' is the lowest ranked elements as the key factors which is used to determine whether outcomes of performance management is effective. The measure used mostly to determine whether performance management is effective is 'improved customer care'. 'Motivation' is one of the least preferred measures to determine whether performance management is effective. 


\section{Managerial Implications}

The following implications or a possible suggestion is made

1. Performance management systems linked to pay and being quantifiable must be done with an employee-centric bent of mind so that employees are aware and satisfied with the quantifiable parameters and rewards linkages.

2. Performance management systems do not distract people from core activities and should not be distanced from payment systems, as per the survey. Also individual and organization goals must be integrated and performance management systems should focus on developmental areas.

3. Most of the participant organizations has a business strategy focusing on improved quality and increased productivity and less focus on reducing headcounts, so companies that adhere to the above 2 implications may boost their productivity and quality levels and keep headcount stable.

4. Competence assessments and Objective-setting review are very effective methods of appraisal.

5. Performance management is not bureaucratic and needs to be defined clearly as to how it is linked to pay.

6. A good performance management system leads to 'improved customer care' though not necessarily related to more 'motivated employees'. This justifies performance linked pay as a 'Hygiene' factor in the 'Hygiene-motivation' theory concept.

\section{Limitations and Directions for Future Research}

The research analyzed performance management systems of 111 firms. These were mainly from the Indian sectors. The research may be further extended to only the private sector or only the public sector. The research focused mainly on 111 companies. It may be further resolved to study even more companies so that more information could be gathered to find out details of such cases of companies.

\section{References}

1. Cecchi-Dimeglio, P. (April 12, 2017). Performance Management: How gender bias corrupts performance reviews, and what to do about it. Harvard Business Review.

2. Frigo, M. (105 (2000)). 2000MG Survey on Performance measurement: The Evolution of Performance Measurement Systems. Cost Management Update, 13.

3. Govt. of India, I. D. (2015, March 24). Industry Sector: Advantage India, India in Business. Retrieved October 5, 2015, from India in Business, Ministry of External Affairs, Govt. of India, Investment and Trade Promotion (ITP) Division: http://indiainbusiness.nic.in/newdesign/index.php?param=advantage/167\#

4. Govt. of India, ITP Division, I. (2014, June). Services Sector: Advantage India, India in Business. Retrieved from India in Business, Ministry of External Affairs, Govt. of India, Investment and Trade Promotion (ITP) Division: http://indiainbusiness.nic.in/newdesign/index.php?param=advantage/169\# 
5. Govt. of India, ITP Division, I. (2015, February). Services Sector: Advantage India, India in Business. Retrieved October 5, 2015, from India in Business, Ministry of External Affairs, Govt. of India, Investment and Trade Promotion (ITP)

Division: http://indiainbusiness.nic.in/newdesign/index.php?param=advantage/169\#

6. Marr, B., Neely, A., Bourne, M., Kennerley, M., Franco, M., Wilcox, M., et al. (2004). Business Performance Measurement: What is the State of the Art in Large U.S. Firms? Proceedings of the 4th International Conference on Performance Measurement. Edinburgh, Scotland: Neely, A.D.; Kennerley, M.;.

7. Neely, A., \& Najjar, M. A. (2006). Management Learning Not Management Control: The True Role of Performance Measurement. California Management Review, 101-102.

8. O'Boyle, E. J. (2012). The best and the rest:Revisiting the norm of normality of individual performance. Personnel Psychology, 65 (1), 79-119.

9. Rigby, D. (43/2 (Winter 2001)). Management Tools and Techniques: A Survey. California Management Review, 139-160.

10. Speckbacher, G., Bischof, J., \& Pfeiffer, T. (14/4 (December 2003)). A Descriptive Analysis on the Implementation of Balanced Scorecards in GermanSpeaking Countries. Management Accounting Research , 361-387.

\section{About Our Authors}

Merlyn Michael D'souza is an assistant professor in Human Resource Management at IES Management College and Research Centre. She earned her M.M.S. (Personnel), from IES Management College and Research Centre, Bandra, of Mumbai University. She has over 3 years of industry experience and 9+ years of teaching experience. She was employed as an Associate Consultant - Project Management with a leading automotive consulting firm. She handled jobs related to Recruiting \& Selecting prospective Trainers and also conducted Training projects. She has also authored research papers and attended national and international conferences in HR.

Michael D'souza is an assistant manager in Human Resource Management at Bank. He is a B.Com. From St. Andrew's College of Arts, Science and Commerce, Bandra, Mumbai, of Mumbai University and has earned his M.B.A. (Human Resources Management), from Sikkim Manipal University. He has over 10+ years of experience in the HR functional roles. He has also authored HR research papers and attended conferences in HR. 